\title{
REFÚGIO NO CONE SUL: ANÁLISE COMPARADA SOBRE O DIREITO DOS REFUGIADOS NA ARGENTINA E BRASIL
}

\author{
REFUGE IN THE SOUTHERN CONE: COMPARATIVE \\ ANALYSIS ON THE RIGHTS OF REFUGEES IN ARGENTINA \\ AND BRAZIL
}

\section{REFUGIO EN EL CONO SUR: ANÁLISIS COMPARATIVO SOBRE LOS DERECHOS DE LOS REFUGIADOS EN ARGENTINA Y BRASIL}

\author{
Tatiana de A. F. R. Cardoso Squeff* \\ Romeu Vaz Pinto Neto**
}

\begin{abstract}
1 Introdução. 2 Bases legais de proteção de refugiados na Argentina e no Brasil. 3 Proteção jurídica nacional: pontos convergentes e divergentes das Legislações Brasileira e Argentina em sede de refúgio. 4 Procedimento declaratório de refúgio na Argentina e no Brasil: peculiaridades quanto à obtenção do status de refugiado. 5 Considerações finais. Referências.
\end{abstract}

\section{RESUMO}

$\mathrm{O}$ presente artigo visa analisar sob a perspectiva comparada as questões atinentes ao refúgio em dois países do cone sul, a saber, na Argentina e no Brasil, na tentativa de averiguar, sob um olhar normativo, qual ordenamento jurídico recepcionaria melhor os refugiados em seu território. Nesse sentido, três níveis de comparação são feitos: (1) quanto às regras aplicáveis nos ordenamentos brasileiro e argentino; (2) quanto aos direitos previstos nas normativas domésticas destes Estados, para além daquelas positivadas em nível internacional e acatadas pelos mesmos; e (3) quanto ao procedimento a ser cumprido para requerer-se refúgio nesses países. Para tanto, desde uma análise histórico-descritiva e de um recorte qualitativo, foi realizada uma pesquisa

* Doutora em Direito Internacional pela UFRGS (2018), com período sanuíche junto à Universidade de Ottawa. Mestre em Direito Público pela Unisinos (2012). Pós-graduada em Relações Internacionais Contemporâneas pela UFRGS (2015), em Direito Internacional Público, Privado e da Integração Regional pela UFRGS (2009) e em Língua Inglesa pela Unilasalle (2008). Professora Adjunta de Direito Internacional da Universidade Federal de Uberlândia, Uberlândia, MG, BR. E-mail: <tatiafrcardoso@gmail.com>. http://orcid.org/0000-0001-9912-9047

** Bacharel em Direito - UniRitter. Integrante do Grupo de Pesquisa "Igualdade, discriminação e diferença" (UniRitter). Advogado do Núcleo de Apoio e Assessoria a refugiados e imigrantes - NAARI (UniRitter), Porto Alegre, RS, BR. E-mail: <Romeu.vpn@gmail.com>. http://orcid.org/0000-0002-3950-7875 
majoritariamente documental e, em menor escala, bibliográfica. Ao final, uma vez obtidos esses elementos, desde uma abordagem exploratória, notou-se que a lei argentina é mais benéfica aos refugiados quando comparada com a lei brasileira, de modo que, se essa informação fosse conhecida, poderia colaborar para um influxo maior de refugiados à Argentina.

Palavras-chave: Refúgio. Brasil. Argentina. CONARE.

\begin{abstract}
From a comparative perspective, the present article aims at analyzing the issues related to refuge in two countries of the Southern Cone, namely Argentina and Brazil, in an attempt to ascertain, under a normative standpoint, which legal order would better receive the refugees in its territory. In this sense, three levels of comparison are made: (1) regarding the rules applicable in the Brazilian and Argentinean orders; (2) in respect of the rights provided for in the domestic regulations of these States, in addition to those established at international level and respected by them; and (3) as to the procedure to be followed in order to seek refuge in those countries. To do so, parting from a historical-descriptive analysis approach and from a qualitative method of selection, a (predominantly) documental and (to a lesser extent) bibliographical research was carried out. In the end, once all elements have been obtained, from an exploratory approach, it has been observed that Argentine law is more beneficial to refugees when compared to Brazilian law, thus, leading to the conclusion that, if this information was known, it could lead to a greater influx of refugees to Argentina.
\end{abstract}

Keywords: Refuge. Brazil. Argentina. CONARE.

\title{
RESUMEN
}

Desde una perspectiva comparativa, el presente artículo tiene como objetivo analizar los problemas relacionados con el refugio en dos países del Cono Sur, a saber, Argentina y Brasil, en un intento de determinar, bajo un punto de vista normativo, qué orden legal recibiría mejor a los refugiados en su territorio. En este sentido, se realizan tres niveles de comparación: (1) con respecto a las reglas aplicables en los pedidos brasileños y argentinos; (2) con respecto a los derechos previstos en las regulaciones nacionales de estos Estados, además de los establecidos a nivel internacional y respetados por ellos; y (3) en cuanto al procedimiento a seguir para buscar refugio en esos países. Por lo tanto, a partir de un enfoque de análisis histórico-descriptivo y de un método de selección cualitativo, se llevó a cabo una investigación (predominantemente) documental y (en menor medida) bibliográfica. Al final, una vez que se han obtenido todos los elementos, desde un enfoque exploratorio, se ha observado que la ley argentina es más beneficiosa para los refugiados en comparación con la ley brasileña, lo que lleva a la conclusión de que, si se conociera esta información, podría conducir-se a una mayor afluencia de refugiados a la Argentina.

Palabras clave: Refugio. Brasil. Argentina. CONARE. 


\section{INTRODUÇÃO}

"Das 65,6 milhões de pessoas forçadas a deixar seus locais de origem, 22,5 milhões são consideradas refugiados - isso sem contar os cerca de 2,8 milhões de pessoas que se encontram na situação de solicitantes de refúgio, perfazendo o número mais alto de todos os tempos.” (ACNUR, 2017a, online). Destes refugiados já declarados, 9.552 encontram-se no Brasil número que aumentou 12\% no último ano (ACNUR, 2017a) e que tende a aumentar ainda mais em 2017 com a crise venezuelana, haja vista que o próprio número de solicitantes deste país vizinho tenha aumentado em 307\% quando comparado a 2015 (ACNUR, 2016a). No Cone Sul, todavia, o Brasil não é o único Estado que tem recebido um influxo considerável de refugiados, sendo seguido por Chile (cerca de 6.000), Argentina (cerca de 5.000), Bolívia (cerca de 700), Uruguai (cerca de 600) e Paraguai (cerca de 200) (ACNUR, 2016b).

Frente a essa situação, questiona-se: será que a legislação poderia ser considerada um fator de atração de refugiados ao Cone Sul? Noutros termos, para além de fatores como o idioma, a proximidade territorial e/ou cultural, a situação econômico-política do país de destino, haveria alguma previsão normativa doméstica que pudesse, se conhecida, atrair mais refugiados para certa nação? Por certo que para a realização de uma pesquisa desse porte seria imprescindível um espaço maior. Nesse escopo, delimita-se o presente estudo nas legislações brasileira e argentina, a fim de verificar, comparativamente, se há algum motivo legal para justificar a escolha por uma destas nações, as quais apresentam o $1^{\mathrm{a}}$ e o $3^{\mathrm{a}}$ maiores índices de acolhimento no cone sul. Nesse sentido, três níveis de comparação são feitos: (1) quanto às regras aplicáveis nos ordenamentos brasileiro e argentino; (2) quanto aos direitos previstos nas normativas domésticas destes Estados, para além daquelas positivadas em nível internacional e acatadas pelos mesmos; e (3) quanto ao procedimento a ser cumprido para requerer-se refúgio nesses países.

Para tanto, a partir do método hipotético-dedutivo, realiza-se uma pesquisa de natureza aplicada, no âmbito do Direito Internacional, cujos elementos normativos serão expostos desde um viés descritivo e comparativo, para que, ao cabo, possa-se explorar qual legislação seria mais benéfica para refugiados. Ademais, quanto aos métodos empregados, essa pesquisa envolve o uso variado de técnicas de coleta de dados, as quais, uma vez selecionadas qualitativamente, incluem não apenas uma pesquisa bibliográfica para uma análise histórica e descritiva dos procedimentos empregados para o reconhecimento do instituto do refúgio e a sua respectiva concessão de direitos; mas especialmente de uma pesquisa documental de dados obtidos através da Organização Internacional para Migração (OIM), do Comitê Nacional para Refugiados brasileiro e argentino, da Agência das Nações Unidas para Refugiados (ACNUR), além das próprias leis internas do Brasil e da Argentina atinentes a refúgio.

\section{BASES LEGAIS DE PROTEÇÃO DE REFUGIADOS NA ARGENTINA E NO BRASIL}

O refúgio no Brasil foi regulado a partir da Lei Federal 9.474 de 1997 (BRASIL, 1997); porém, muito antes de ser sancionada essa legislação, o Brasil já era parte dos grandes instru- 
mentos internacionais de proteção a refugiados firmados ao final da Segunda Guerra Mundial, quais sejam, a Convenção relativa ao Estatuto dos Refugiados, concluída em Genebra, em 28 de julho de 1951; e o Protocolo sobre Estatuto dos Refugiados, concluído em Nova York, em 31 de janeiro de 1967.

Isso porque, o Brasil sempre foi um país de destino de migrantes ${ }^{1}$, de modo que participar de tais instrumentos se mostrava imperativo para sanar as lacunas legais existentes no que tange aos seus direitos e demais proteções a serem conferidas pelo Estado de acolhida. Por isso, internalizara tais instrumentos legais no ano de 1961 (Decreto n. 50.215) e 1972 (Decreto n. 70.946), respectivamente - sendo, inclusive, o primeiro país do Cone Sul a ratificar o texto da Convenção de Genebra.

Apesar disso, cabe lembrar que a citada Convenção possuía tanto uma reserva temporal, visto que somente poderiam ser refugiados aqueles indivíduos perseguidos por atos pretéritos à 31 de janeiro de 1951, quanto geográfica, a qual conceituava como refugiados somente aqueles que eram perseguidos no ambiente Europeu (JUBILUT, 2007, p. 171-172) - restrições essas que são retiradas, respectivamente, através da ratificação do Protocolo de 1967, bem como pela edição dos Decretos de n. 98.602/89 e 99.757/90².

Logo, com a redemocratização e à luz dos princípios norteadores da Constituição de 1988, pode-se dizer que uma nova página inicia-se no Brasil no que tange à recepção de pessoas em situação de hipervulnerabilidade, tal como os refugiados, que resta coroada pela introdução, no ordenamento nacional, da citada Lei Federal 9.474/97 - considerada um modelo pelo ACNUR pela previsão ampliada de reconhecimento de refugiados, já incluindo no inciso III do artigo $1^{\circ}$, enquanto categoria possível de perceber tal status as pessoas que fogem de graves e generalizadas violações de direitos humanos (MILESI; CARLETI, 2012, p. 85; BRASIL, 1997). ${ }^{3}$

O Brasil, através desse conjunto normativo, criou o Comitê Nacional para Refugiados (CONARE) - órgão de composição interministerial, porém, vinculado ao Ministério da Justiça, que ficou responsável pela análise e decisão sobre as solicitações de refúgio no Brasil e pela política nacional atinente aos refugiados (DURÃES; OLIVEIRA, 2014, p. 16). Acerca disso, Barreto (2010, p. 19) entende que a "maior novidade desse órgão é que ele é

1 Importante que se confira os textos de Oliveira (2013) e Carneiro e Collar (2012) acerca dos fluxos migratórios ao Brasil - aquele em relação aos eventos da Segunda Guerra Mundial e este em relação ao século XX como um todo.

2 Afinal, em virtude do momento histórico em que o Estado se encontrava ainda na década de 1970 - uma ditadura militar - e, em função de uma ruptura da democracia na América Latina como um todo, o Estado brasileiro não tinha interesse em receber opositores de sua forma de governo, mantendo, assim, a reserva geográfica da Convenção de 1951 em receber somente refugiados da Europa, os acontecimentos na América latina em virtude das quebras democráticas e, da África com os processos de independência, geraram diversos grupos de refugiados e, por conta da reserva geográfica que o Brasil havia mantido com a ratificação dos Instrumentos internacionais, não os reconhecia como refugiados (BARBOZA; BACK, 2016, p. 99-100).

3 Por oportuno, cabe referir que essa lei vai ao encontro da forma ampliada de concessão de refúgio trazida pelo direito interamericano, mais especificamente, pela Declaração de Cartagena da Organização dos Estados Americanos (OEA) de 1984 (ANDRADE; MARCOLINI, 2002; ROGUET, 2009). 
misto, é público-privado, e dele participam vários segmentos de governo”, a sociedade civil (por meio das Cáritas Arquidiocesana ${ }^{4}$ ) e até mesmo o ACNUR, com o intuito de "discutir os aspectos de integração social e laboral, de saúde, do diploma e do estudo no Brasil” envolvendo os refugiados.

Por isso diz-se que é com essa legislação que se passou a entender a imperatividade de criar políticas públicas específicas e estender o acesso desses indivíduos àquelas já existentes, demonstrando o amadurecimento do debate do acesso e do tratamento paritário dos refugiados aos nacionais (DOMINGUEZ; BAENINGER, 2016, p. 2), em um fiel cumprimento do previsto no caput do artigo 5 da Carta Política pátria (BRASIL, 1988; GODOY, 2016, p. 54-56), especialmente quanto às "garantias de índole constitucional que o ordenamento positivo brasileiro confere e assegura a qualquer pessoa." (BRASIL, 2008, online).

Até mesmo porque, a Constituição Federal ainda estipula enquanto princípio norteador das suas relações internacionais a prevalência dos direitos humanos (BRASIL, 1988, Art. 4, II), traz a dignidade humana como um de seus fundamentos (BRASIL, 1988, Art. 1, III), bem como estipula enquanto um de seus objetivos a promoção de todos, sem preconceitos de origem, raça, sexo, cor, idade e quaisquer outras formas de discriminação (BRASIL, 1988, Art. 3, IV), de modo que ela igualmente pode ser considerada uma das bases legais para a tutela dos refugiados no território brasileiro (JUBILUT, 2007, p. 179-181; JUBILUT, 2006, p. 24-25).

Assim sendo, conclui-se que são quatro os documentos que compõe a base legal primária da proteção dos refugiados no Brasil, temporalmente concebidos na seguinte ordem: o Decreto n. 50.215/61, o Decreto n. 70.946/72, a Constituição de 1988 e a Lei Federal 9.474/97.5

$\mathrm{Na}$ Argentina, por outra banda, a proteção jurídica aos refugiados tardou ${ }^{6}$, tendo sido sancionada a Ley General de Reconocimiento y Protección al Refugiado, registrada sob o n. 26.165, apenas em 2006. Apesar disso, o fenômeno do refúgio já ocorria em terras castellanas desde, no mínimo, meados do Século XX com as guerras civis (como no Uruguai) e as duas Grandes Guerras (JUBILUT, 2007, p. 23-24; CICOGNA, 2009a), muito embora a análise dos pedidos fosse feita a partir de perspectivas individuais dos grupos deslocados, em que eram expedidos decretos através do poder executivo determinando a sua proteção (CICOGNA, 2012, p. 53).

4 Consoante a própria organização, a Cáritas, entidade não-governamental mundial ligada à Igreja Católica, fundada em 1956, a qual visa a "promoção e atuação social [...] na defesa dos direitos humanos, da segurança alimentar e do desenvolvimento sustentável solidário. Sua atuação é junto aos excluídos e excluídas em defesa da vida e na participação da construção solidária de uma sociedade justa, igualitária e plural”, atuando diretamente na defesa dos interesses de migrantes no país (CÁRITAS, 2019).

5 Salienta-se que a Lei Federal 13.445 de 2017, Lei de Migrações, não versa diretamente sobre refugiados, mas tão-somente de maneira indireta (BRASIL, 2017), motivo pelo qual não se classifica essa lei enquanto parte do núcleo central legal brasileiro para refugiados. Aliás, indiretamente, também se aplicam as normativas de Direitos Humanos as quais o Brasil seja signatário, tal como prescreve o próprio artigo 48 da Lei Federal 9.474 (BRASIL, 1997).

6 Importante que se confira o texto de Novick (2005) acerca da modificação da política migratória argentina desde meados do século XX. 
Na metade do século XX, tal como ocorreu nos países vizinhos, a Argentina também era um país de destino, tendo acolhido - a título exemplificativo - cerca de 30.000 eslovacos no ano de 1947 (CICOGNA, 2012, p. 53; CICOGNA, 2009b). Não obstante, mesmo com a adoção no plano internacional da Convenção de Genebra de 1951, a Argentina veio a ratificá-la apenas em 1962 por intermédio da Ley Nacional de Adhesión n. 15.869; por outro lado, ratificou no mesmo ano em que foi celebrado o Protocolo de Nova York de 1967 com a introdução no ordenamento pátrio da Ley Nacional de Adhesión n. 17.468 (CICOGNA, 2012, p. 53) - tratados esses que só viriam a realmente surtir grande impacto no ordenamento nacional em 1992 quando a Corte Suprema de Justiça de la Nación Argentina passou a adotar um posicionamento monista em relação ao direito internacional, acabando por desencadear uma reforma constitucional em 1994, a qual oficialmente previa a supremacia da ordem internacional em sua Constituição Nacional (POSSE, 1995, p. 261).

Em 1985, o Poder Executivo Argentino criou o Comité de Elegibilidad para los Refugiados (CEPARE) através do Decreto n. 464/85, sendo esta a instituição pública responsável para o trâmite das solicitações de refúgio, a coleta de dados estatísticos de solicitações, como também para formular políticas públicas para estes migrantes (NIEVAS; BELLO; MARCOGLIESE, 2012, p. 55-56). Entretanto, tal órgão manipulou de forma desordenada as informações provocando a perda e a destruição de dados e expedientes referentes às solicitações (NEJAMKIS; NIEVAS, 2012, p. 451). Inclusive, é o CEPARE que incorporou ao ordenamento argentino, através da Ata Resolutiva n. 465/98, os termos da Declaração de Cartagena de 1984, cujas deliberações na Colômbia ela não havia participado (NEJAMKIS; NIEVAS, 2012, p. 452-453).

Ato contínuo, em 2003, foi sancionada na Argentina a Ley Migratória, de n. 25.871 , a qual apesar de não dispor diretamente sobre refúgio, mostra-se importantíssima, por introduzir a temática migratória aos debates de direitos humanos, particularmente por reconhecer o direito humano de migrar no artigo 4 (NICOLAO, 2010; ARGENTINA, 2003). Já em 2006, como aludido supra, foi sancionada a Ley General de Reconocimiento y Protección al Refugiado sob o n. $26.165^{9}$, derrogando o Decreto n. 464/85, criando a Comisión Nacional para los

7 Cf. caso Ekmekdjian, Miguel Angel c/ Sofovich, Gerardo y otros em que se estabeleceu que, um tratado ratificado pelo governo argentino era diretamente aplicado ao direito interno, ainda que não houvesse norma interna regulando os direitos previstos no tratado (ARGENTINA, 1992).

8 Esta lei veio a substituir a Ley de Migraciones y Fomento de la Inmigración, de n. 22.439 de 1981, a qual tinha como objetivo regular a migração - em geral - na Argentina. Esse é um ponto interessante, posto que essa lei havia sido forjada sob o escopo do regime militar daquele pais, guardando grande semelhança com o Brasil, o qual, em 1980, havia editado o Estatuto do Estrangeiro - Lei Federal 6.815 -, a qual era regida pelo mesmo princípio que a legislação argentina, qual seja, o da segurança nacional (BRUMAT; TORRES, 2015). Ademais, outro ponto de contato é exatamente a revogação de ambas as leis arquitetadas nos períodos de chumbo em ambas as nações já no século XXI (muito embora a Argentina tenha o feito muito antes que o Brasil, como indiretamente se apontará neste texto).

9 Insta dizer que dois anos antes de sua edição, a Argentina promulgou a Ley de Migraciones n. 25.871/04, trazendo a política migratória argentina, os direitos e deveres dos estrangeiros e as atribuições do Estado, tangenciando em alguns artigos a temática do Refúgio, tal como o artigo 31 (documentos), para citar um exemplo (ARGENTINA, 2004). 
Refugiados (CONARE), sob jurisdição do Ministério do Interior, passando a ter as funções antes atribuídas ao CEPARE, o qual foi extinto em 2009 após completar a transição entre os referidos órgãos (NEJAMKIS; NIEVAS, 2012, p. 452-453).

Além disso, essa legislação é tida como "inovadora em matéria de direitos humanos, sendo considerada um avanço sem precedentes com relação ao tratamento mais favorável e de interpretação mais favorável a pessoa [refugiada]" (ROCIO, 2010, p. 4). Isso porque, em seus três primeiros artigos já anuncia que a Argentina não só adiria a todos os tratados sobre o tema, como também dispõe claramente que a proteção desse tipo de migrante seguiria obrigatoriamente o direito internacional dos direitos humanos (ROCIO, 2010, p. 4).

E mais recentemente, em 2016, tendo em visto a grande população sírio-libanesa que se encontra em território argentino e o seu aumento do fluxo migratório, o governo, preocupado com a situação, através do Decreto Nacional n. 1.034 de 2016, criou o Gabinete Nacional del Programa Síria com a específica finalidade de recepção humanitária de refugiados sírios oriundos da República Árabe Síria, propondo ações de integração social (ARGENTINA, 2016, art. 1\%).

Por fim, mas não menos importante, no que tange a Constituição da República Argentina de 1995, cumpre destacar o artigo 20, segundo o qual os estrangeiros gozam de todos os direitos civis do cidadão argentino, não estando obrigados a assumir a cidadania e, ainda, podendo requerer naturalização após residirem dois anos em território argentino cumprindo os requisitos legais (ARGENTINA, 1995). Ademais, o artigo 25, tece que o governo fomentará a imigração europeia, bem como não irá restringir ou limitar a entrada de estrangeiros que tenham como fito laborar na terra, melhorar as indústrias locais, e introduzir e ensinar ciências e artes (ARGENTINA, 1995). Essa previsão, note-se, por mais que estabeleça os objetivos para a recepção de imigrantes, mostra-se uma normativa importante, posto que dialoga diretamente com o preâmbulo da Carta Política, assegurando a liberdade "para todos los hombres del mundo que quieran habitar en el suelo argentino” (ARGENTINA, 1995, preâmbulo).

Assim sendo, conclui-se que são igualmente quatro os documentos vigentes que compõe a base legal primária de proteção dos refugiados na Argentina, quais sejam, a própria Constituição de 1995, a Ley n.15.869/62, a Ley n. 17.468/67, e a Ley n. 26.165/06 (já que o Decreto n. 1.034/16 dirige-se especificamente aos sírios).

\section{PROTEÇÃO JURÍDICA NACIONAL: PONTOS CONVERGENTES E DI- VERGENTES DAS LEGISLAÇÕES BRASILEIRA E ARGENTINA EM SEDE DE REFÚGIO}

O primeiro ponto convergente entre Argentina e Brasil no que tange a proteção de refugiados a ser destacado é exatamente que ambas as nações em comento são partes de tratados internacionais sobre o tema, o que, na verdade, apenas imprime o mesmo conjunto de obrigações às quais os dos países deverão seguir em suas condutas no trato deste tipo específico de migrante. Outrossim, uma questão que justamente fará com que haja, potencialmente, uma nação normativamente mais benéfica para a recepção de refugiados, 
é a forma em que esses indivíduos serão tratados na órbita doméstica. Logo, impende destacar a tutela jurídica conferida especificamente pelas leis que versam sobre o refúgio nos ordenamentos nacionais em apreço, a fim de que possam ser ressaltadas as suas semelhanças e divergências nesse aspecto.

O primeiro ponto convergente diz respeito a ambos os Estados possuírem legislação específica regulando o Estatuto dos Refugiados, seja a Lei Federal n. 9474/97, no Brasil, e a Ley General n. 26.165 na Argentina. Nelas é que se encontra o conceito de refugiado, dentre os quais estão tanto os motivos clássicos como a visão ampliada trazida pelo "espírito de Cartagena”. Entretanto, o Brasil (1997, online, art. 1, III) limita-se a internalizar somente a "violação massiva de direitos humanos" enquanto a Argentina (2006, online, art. 4), além deste conceito, positiva como motivos "a agressão estrangeira, os conflitos internos, e outras circunstâncias que tenham perturbado gravemente a ordem pública.” Logo, verifica-se que a legislação argentina é mais ampla positiva e subjetivamente, tendo internalizado por completo o conceito trazido na Declaração de 1984 da OEA.

Outro ponto divergente entre a Lei Federal n. 9.474 brasileira e a Ley General n. 26.165 argentina é a possibilidade da 'extensão familiar' ao companheiro: as duas leis trazem a extensão aos cônjuges, entretanto, somente a lei argentina traz a questão da afetividade, o que se lê como união estável (ARGENTINA, 2006, online, arts. 5 e 6). Observa-se que o motivo de não constar na lei brasileiro a mesma previsão é porque esta foi realizada antes da reforma do Código Civil de 2002, sendo assim, não contemplava a possibilidade da união estável no ordenamento jurídico brasileiro.

Contudo, a Lei de Migrações brasileira, Lei Federal n. 13.445/17, subsidiariamente aplicável à temática, trouxe a questão da parentalidade por afinidade ou sócio-afetividade para a concessão de autorização de residência (BRASIL, 2017, art. 37), o qual é concedido aos refugiados após o trâmite do processo de solicitação de refúgio (BRASIL, 2017, art. 30, II, e). Ainda, a citada legislação concede o mesmo tipo de visto aos ascendentes ou descendentes até o segundo grau ou irmão de brasileiro (BRASIL, 1997, art. 2; BRASIL, 2017, art. 37), diferentemente da Lei Argentina, que concede o visto somente até o primeiro grau de parentesco (ARGENTINA, 2006, art. 6).

Além do mais, ressalta-se que ambas as leis reforçam o princípio do non-foulement ${ }^{10}$ (BRASIL, 1997, art. 7, §1; BRASIL, 2017, art. 26, §10; ARGENTINA, 2006, art. 2) e o da confidencialidade em todas as etapas do procedimento de solicitação de refúgio (BRASIL, 2017, art. 23; ARGENTINA, 2006, art. 32), e ainda, preveem a possibilidade de expulsão

10 Refere-se à impossibilidade de proceder-se com a devolução de um migrante (refugiado ou não), ao seu país de origem ou a qualquer outro quando este possa sofrer em tal país de destino violação dos seus direitos básicos, particularmente quanto a sua vida e/ou liberdade, em razão de sua raça, religião, nacionalidade, grupo social ou opinião política (ACNUR, 1951, 33[1]). Outrossim, especificamente quanto aos refugiados, nota-se que a Convenção de Genebra de 1951 estabelece que tal benefício não poderá ser invocado quando o refugiado ocasionar sérios riscos à segurança do país ou quando o mesmo tenha sido condenado por crime grave, constituindo ele mesmo em uma ameaça ao país, constituindo-se em exceções ao referido princípio (ACNUR, 1951, $33[2])$. 
do migrante no caso de apresentar risco à segurança nacional e à ordem pública (BRASIL, 1997, art. 36; ARGENTINA, 2006, art. 8).

Na Argentina (2006, art. 8), existem critérios abstratos a serem avaliados como o fato de a medida ser razoável, adequada e proporcional ao risco que o migrante apresenta, levando-se em consideração os direitos afetados pela medida e o interesse da sociedade para que seja realizada a sua expulsão, critérios estes, inexistentes nas legislações brasileiras. Contudo, como anteriormente referido, ambas as legislações incluem a impossibilidade de devolução, onde possam sofrer tortura, maus-tratos e penas cruéis, desumanas ou degradantes e propõem um prazo razoável para expulsão do migrante a um terceiro país em que seja garantida a sua vida, liberdade e segurança pessoal.

No que concerne à exclusão da condição de refúgio, ou seja, hipóteses em que sequer será reconhecida, a legislação argentina traz, negativamente, a presunção de que o solicitante de refúgio tenha cometido um crime comum, fora do país, antes de ser admitido como refugiado (ARGENTINA, 2006, art. 9), enquanto a legislação brasileira somente prevê a exclusão nos casos de crimes graves, cometidos contra a paz, crime de guerra, contra a humanidade ou crime hediondo (BRASIL, 1997, art. 3, III). Mostra-se aqui que a legislação argentina prejudica o refugiado em excluí-lo da condição apenas por um crime comum, em relação à legislação brasileira, que prevê essa exclusão apenas para crimes graves.

Mesmo sendo uma inovação legislativa aparentemente negativa, a legislação brasileira inclui nas hipóteses de exclusão da condição de refugiados os atos terroristas ou tráfico de drogas (BRASIL, 1997, art. 3, III), previsões estas que sequer constam nos documentos internacionais. Todavia, pode-se visualizar estas hipóteses como uma leitura contemporânea das convenções internacionais referentes ao tema, adaptando-as aos principais crimes transacionais do final do Século XX e início do Século XXI.

A respeito da cessação da condição de refugiado as legislações brasileira e argentina trazem as mesmas possibilidades (BRASIL, 1997, art. 38; ARGENTINA, 2006, art. 11). Não obstante, a legislação argentina positiva também a possibilidade de o refugiado exercer o contraditório em relação à decisão que cessar a sua condição, podendo ainda alegar que, apesar das mudanças em seu país de origem, os motivos que ensejaram o seu refúgio ainda persistem. Há de se notar também que os dois Estados criaram órgãos especiais para receber as solicitações de refúgio, deliberar em primeira instância e proteger os direitos dos refugiados (BRASIL, 1997, art. 11; ARGENTINA, 2006, art. 18; CALLUM, 2012, p. 34), os quais coincidentemente são chamados de CONARE!

As legislações brasileira e a argentina preveem os direitos civis, sociais, econômicos e culturais igualmente a qualquer outro migrante que esteja em território nacional (ARGENTINA, 2006, art. 52), em que pese o Brasil tenha tardado em fazê-lo, vez que incluída apenas em 2017 com a promulgação da Lei de Migrações (BRASIL, 2017, art. 4, I). No entanto, nota-se que até o presente momento não há previsão de direitos políticos plenos aos refugiados em nenhuma das duas legislações nacionais. 
Todavia, pontualmente acerca disso, cabe destacar que no Brasil, existe um Projeto de Emenda Constitucional (PEC) com fito de estender o direito político aos migrantes ${ }^{11}$ - refugiados ou não. Já na Argentina, apesar do código eleitoral expressar que somente nacionais ou naturalizados tem direito de voto em nível nacional, as legislações de todas as 23 províncias da Argentina e da Capital Federal possuem previsão do direito ao voto de migrantes em eleições municipais e provinciais (MOREIRA, 2013, p. 70-73). Além do mais, corre no Senado argentino um Projeto de Lei para que seja alterado o Código Eleitoral com o propósito de estender o voto aos migrantes com visto de residência permanente por mais de um ano no país (SUED, 2012).

Por fim, as legislações dos dois Estados positivam as soluções duráveis destinadas a oferecer respostas à realidade enfrentada pelos refugiados no local em que se encontram, particularmente quanto ao resguardo e a efetivação de seus direitos (MADUREIRA, 2015), como repatriação (BRASIL, 1997, art. 42; ARGENTINA, 2006, art. 25), integração local (BRASIL, 1997, arts. 43 e 44; ARGENTINA, 2006, art. 12) e o reassentamento (BRASIL, 1997, arts. 45 e 46; ARGENTINA, 2006, art. 25). A legislação argentina, porém, prediz que, em caso de ingresso massivo de refugiados, será utilizado um critério de determinação por grupo, sendo que um refugiado por pertencer a um conjunto de indivíduos afetados (dialogando com a prática de longa data da argentina como narrada no ponto anterior), poderá solicitar assessoramento do ACNUR para solucionar e buscar a efetiva proteção (ARGENTINA, 2006, arts. 54 e 55).

\section{PROCEDIMENTO DECLARATÓRIO DE REFÚGIO NA ARGENTINA ENO BRASIL: PECULIARIDADES QUANTO À OBTENÇÃO DO STATUS DE REFUGIADO}

O procedimento de solicitação de refúgio no Brasil e Argentina apresentam, igualmente, pontos convergentes e divergentes, de modo que a sua análise também deva ser realizada para fins de averiguar - se possível - qual legislação mostra-se mais atrativa normativamente para recepcionar indivíduos que, uma vez saindo de seus países de origem, terminem por buscar os países do cone sul em debate.

Logo, inicialmente, cabe dizer que enquanto no Brasil o solicitante de refúgio deve buscar a autoridade de fronteira ou a Polícia Federal caso já se encontre em território nacional (BRASIL, 1997, arts. 7 e 17), o requerimento de refúgio, na Argentina, é feito através da Secretaria Executiva do CONARE, ou, ainda, através de vários órgãos, quais sejam, uma delegação ou oficina migratória da Direção Nacional de Migrações, qualquer autoridade nacional, provincial ou municipal, ou até mesmo a polícia migratória da fronteira (ARGENTINA, 2006, arts. 39 e 41).

11 Trata-se da PEC 25/2012, de autoria ex-Senador, Aloysio Nunes (PSDB-SP) - atual Ministro das Relações Exteriores brasileiro. Ela tem como objetivo alterar os arts. $5^{\circ}, 12$ e 14 da Constituição para estender a estrangeiros direitos inerentes aos brasileiros e conferir aos estrangeiros com residência permanente no país o direito a votar e se candidatar nas eleições municipais - PEC essa que atualmente está pronta para ir ao plenário no Senado (BRASIL, 2012). 
Note-se que o início do processo fora da Polícia Federal pode trazer muitos aspectos positivos, visto que os refugiados já buscam deslocar-se de seus Estados de origem por perseguições, na maioria das vezes, realizadas por figuras estatais, além de, em muitos casos, adentrarem o país de destino de forma ilegal, de modo que é naturalmente lógico que possuam uma resistência em procurar uma entidade policial com intuito de buscarem seus direitos enquanto refugiados, com receio de também sofrerem maus-tratos, perseguição, deportação, etc. Assim, a legislação argentina mostra-se muito positiva nesse sentido.

E a legislação argentina não é apenas posit iva por isso, senão também pela previsão de o solicitante de refúgio ter direito a ser assistido por um advogado de forma gratuita (ARGENTINA, 2006, art. 32) - ato este que não encontra equivalência na legislação brasileira, dependendo, assim, muitas vezes de Organizações Não-Governamentais durante o pedido. Por certo que a Constituição Federal brasileira prevê no artigo 134, caput, que a Defensoria Pública deve promover os direitos humanos ${ }^{12}$, o que envolve atuar na defesa de refugiados; porém, muitas vezes esses indivíduos não têm nem ao menos essa informação no Brasil, haja vista a falta de divulgação dessa atuação (BRASIL, 1988).

$\mathrm{Na}$ lei argentina, ainda, há previsão direta acerca da gratuidade do pedido (ARGENTINA, 2006, arts. 32), o que, muito embora no Brasil também o seja, não há previsão legal quanto a isso. Além disso, na lei argentina, prevê-se que o solicitante de refúgio será assistido por um intérprete ou tradutor qualificado em todo o processo de solicitação, gratuitamente, caso não fale o idioma nacional (ARGENTINA, 2006, arts. 32).

No Brasil (1997, online, art. 9), tem-se que a autoridade de fronteira que recebe o solicitante, "deverá ouvir o interessado e preparar termo de declaração, que deverá conter as circunstâncias relativas à entrada no Brasil e às razões que o fizeram deixar o país de origem”, o que, por certo, depende de intérprete e que, por força disso, termina muitas vezes por atrasar o procedimento (MARTIN, 2014). Não só isso, veja-se a importância deste direito, haja vista o idioma ser uma das grandes dificuldades enfrentadas pelos refugiados no país, especialmente no que tange a terem seus direitos explicitados de forma clara e inteligível (GARBINI; SQUEFF; SANTOS, 2018, p. 39-44), o que termina por torná-los hipervulneráveis, devendo ser, por força disso, reparado à luz do devido processo legal e da primazia dos direitos humanos.

Com relação à expedição do protocolo de solicitação de refúgio - fase que, no Brasil, segue a assinatura do termo de declaração - e que servirá como identidade para o solicitante

12 Consoante Peixoto (2017, online), "[a] Defensoria Pública da União (DPU) atua nos casos relativos ao procedimento de solicitação de refúgio, benefícios assistenciais, negativa de carteira de trabalho provisória etc. Destaca-se a participação da DPU em reuniões do CONARE com direito a voz desde 2012 e nas entrevistas dos refugiados nos procedimentos de solicitação. Não se pode olvidar da propositura de três ações coletivas da DPU para: (i) garantir as prerrogativas de vista, intimação pessoal e prazo em dobro nos procedimentos de solicitação de refúgio; (ii) emissão de carteira de trabalho e (ii) motivação das decisões de indeferimento dos pedidos de refúgio. [Já] as Defensorias Públicas dos Estados, por sua vez, têm a atribuição em possíveis matérias criminal, cível, infância e juventude (por exemplo, vaga em creche para criança refugiada sem documento, criança em situação de risco), família (por exemplo, guarda pelo responsável refugiado, mas sem documentos da criança refugiada), Fazenda Pública (por exemplo, medicamentos) etc.". 
e seus familiares, regularizando as suas permanências no Estado e concedendo-lhes direito a retirar CPF e Carteira de Trabalho (BRASIL, 1997, art. 21, §1, §2 e §13), a legislação brasileira, através da Resolução Normativa n. 18 do CONARE (BRASIL, 2014), expressa que este documento deve ser expedido imediatamente pela Polícia Federal e independente da oitiva do solicitante que poderá ser marcada para data posterior. Já na lei argentina, há previsão de um prazo de 20 dias úteis para a expedição da documentação e de 30 dias úteis do registro para a solicitação de permissão de trabalho (ARGENTINA, 2006, art. 42).

Constata-se que este protocolo de solicitação é de suma importância para a manutenção do indivíduo no Estado, posto que é somente com ele que o solicitante de refúgio poderá fixar residência e trabalhar legalmente. A diferença entre o Brasil e a Argentina, nesse ínterim, não é de qual sistema mostra-se mais rápido, mas sim a previsão de notificação das autoridades competentes para prover assistência humanitária aos refugiados e suas famílias, dando-lhes alojamento, acesso à saúde, alimentação e educação enquanto aguardam os documentos serem expedidos (ARGENTINA, 2006, art. 42).

Ao mesmo tempo, pode-se citar também a preocupação na legislação argentina com a prestação de assistência especializada psicológica às mulheres e crianças que, durante o processo de fuga, sofreram violências e violações de seus direitos. Isso porque, a lei argentina prevê o apoio especializado às vítimas (ARGENTINA, 2006, arts. 31, alínea f, e 53), enquanto a legislação brasileira é omissa, apesar de o Brasil ser signatário das Convenções que tratam sobre a proteção especial destes indivíduos mais vulneráveis.

O pedido de refúgio protocolizado junto à autoridade competente segue em ambos os países para a análise do CONARE. Da sua decisão advém um ato declaratório, devendo conter todos os fatos e fundamentação legal que motivaram ou não a concessão da solicitação de refúgio (BRASIL, 1997, art. 26; ARGENTINA, 2006, art. 49). Sendo positiva a resposta, o solicitante será diretamente notificado por escrito e receberá um certificado para que possa fixar residência temporária. Com a residência temporária na Argentina, o refugiado poderá iniciar o processo para a obtenção do Documento Nacional de Identidade (DNI) para estrangeiros - os dois processos são gratuitos (ACNUR, 2017b, p. 4).

Já no Brasil, provida a solicitação, o refugiado deverá ser intimado pessoalmente (ou por edital) da decisão para que compareça à Polícia Federal para assinar um Termo de Responsabilidade (BRASIL, 1997, art. 28). A partir de então, poderá retirar outros documentos, como o Registro Nacional de Estrangeiros (RNE) e cédula de identidade (CI), as quais, no Brasil, só se tornaram gratuitas aos refugiados a partir de 2015, quando da edição da Portaria do Ministério da Justiça n. 1.956 em $1^{\circ}$ de dezembro, de modo que essa previsão não está na Lei Federal 9.474/97.

Em caso de decisão negando a concessão do refúgio, na Argentina, o solicitante poderá, no prazo de dez dias úteis, interpor recurso escrito perante a Secretaria Executiva do CONARE direcionado ao Ministro do Interior, havendo prévia intervenção da Secretaria de Direitos Humanos da Nação (ARGENTINA, 2006, art. 50). No Brasil, por outro lado, o recurso é 
feito ao Ministro da Justiça no prazo de 15 dias, contados do recebimento da notificação (BRASIL, 1997, art. 29).

Ato contínuo, na Argentina, após decisão do CONARE, os solicitantes que foram reconhecidos como refugiados e pretendam revalidar seus diplomas de estudo ou precisam da autenticação das autoridades de seu país de origem, podem obter certificações junto às autoridades argentinas, porquanto ela poderá contar com auxílio das autoridades internacionais para alcançar este propósito (ARGENTINA, 2006, online, art. 42). No Brasil, em razão do silêncio normativo, somente em maio de 2016 é que se passou a prever algo semelhante, posto que o "Ministério da Educação aprovou uma resolução que trata da revalidação, por parte de todas as universidades públicas brasileiras, de diplomas de cursos de graduação e do reconhecimento de diplomas de mestrado ou doutorado expedidos por universidades estrangeiras”, simplificando-a no sentido de estabelecer prazos máximos para o procedimento e por fixar parâmetros para a sua concessão, dentre os quais se destaca a possibilidade de, mesmo não estando na posse de seus documentos, o refugiado pode ter seu diploma "revalidado" ao ser submetido à prova de conhecimentos, conteúdos e habilidades relativas ao seu curso (ACNUR, 2016a).

Assim sendo, verifica-se, no que concerne a proteção dos refugiados, que o Brasil tem se esforçado para fornecer instrumentos capazes a assegurar a mais ampla proteção possível e, com isso, integrar o rol de países que priorizam os Direitos Humanos em seu ordenamento jurídico (JUBILUT, 2007, p. 198), muito embora algumas de suas disposições destoam da realidade prática e acabam por tornar o processo moroso, aquém do desejável (SOARES, 2012, p. 226-227). Por outra banda, nota-se que na Argentina a concessão do status de refúgio é regulado por uma lei bem recente, trazendo uma proteção robusta desde a solicitação do refúgio até a concessão definitiva e demonstrando facilidades de acesso e simplificação dos trâmites burocráticos com o propósito de buscar uma solução permanente para a pessoa humana, resguardando a sua dignidade.

\section{CONSIDERAÇÕES FINAIS}

O presente estudo tinha como objetivo central verificar os instrumentos normativos do Brasil e da Argentina que regem o instituto do refúgio, a fim de compará-los em três áreas: (1) quanto às regras aplicáveis nos ordenamentos dessas nações; (2) quanto aos direitos previstos nas normativas domésticas destes Estados; e (3) quanto ao procedimento a ser cumprido para requerer-se refúgio. Isso porque, pretendia-se averiguar se haveria algum aspecto normativo especial para a escolha "preferencial" do Brasil e/ou da Argentina, no âmbito do cone sul, pelos refugiados que se desloquem para a região.

Assim sendo, feita a análise comparativa almejada, conclui-se que as legislações brasileira, em 2019, com 22 anos, e argentina, em 2019 com 13 anos, possuem muito mais similaridades do que divergências. Contudo, ao vislumbrarem-se os aspectos positivos de cada uma das legislações entende-se que a lei argentina é bem mais completa no que tange 
à proteção dos refugiados, sendo mais detalhada do que a lei brasileira - o que, em diversos aspectos, faz com que ela seja melhor no quesito da segurança jurídica e da própria preservação da pessoa humana.

Por mais que assim se conclua, em relação à pergunta realizada ainda na introdução do presente texto, isto é, se haveria algum benefício normativo que pudesse atrair mais refugiados a uma determinada nação do Cone Sul, tem-se como resposta que há benefícios, sim. Nesse escopo, por mais que outros aspectos sejam tipicamente considerados pelos indivíduos em situações de perseguição, como a proximidade do país de destino, o idioma ou a religião e costumes, se as legislações nacionais fossem conhecidas pelos refugiados, talvez, esse também pudesse ser um fator determinante para o deslocamento humano em direção ao cone sul, em particular para a Argentina.

\section{REFERÊNCIAS}

ACNUR. Brasil facilita a revalidação de diplomas estrangeiros. Genebra, 19 maio 2016a. Disponível em: www.acnur.org/portugues/noticias/noticia/brasil-facilita-a-revalidacao-dediplomas-estrangeiros/. Acesso em: 7 dez. 2017.

ACNUR. Tendencias Globales: desplaziamento forzado em 2015. Genebra, 2016b. Disponível em: http://www.acnur.org/fileadmin/scripts/doc.php?. Acesso em: 10 out. 2017.

ACNUR. Tendencias Globales: desplaziamento forzado em 2016. Genebra, 2017a. Disponível em: http://www.acnur.org/fileadmin/scripts/doc.php?. Acesso em: 10 out. 2017.

ACNUR. Guía para refugiados y solicitantes de asilo en Argentina. Genebra. Disponível em: http://www.migraciones.gov.ar/conare/pdf/Solicitud\%20de\% 20estatuto\%20de\%20 refugiado.pdf. Acesso em: 10 out. 2017b.

ACNUR. Dados sobre refúgio no Brasil: solicitacoes de Refúgio: por país de origem (2016). Balanço até dezembro de 2016. Genebra, s/d. Disponível em: www.acnur.org/ portugues/recursos/estatisticas/dados-sobre-refugio-no-brasil/. Acesso em: 7 dez. 2017.

ACNUR. Convenção Relativa ao Estatuto dos Refugiados. Genebra, 1951. Disponível em: https://www.acnur.org/fileadmin/Documentos/portugues/BDL/Convencao_relativa_ao_ Estatuto_dos_Refugiados.pdf. Acesso em: 18 maio 2019.

ANDRADE, José H. Fischer de; MARCOLINI, Adriana. A política brasileira de proteção e de reassentamento de refugiados: breves comentários sobre suas principais características. Revista Brasileira de Política Internacional, Brasília, v. 45, n. 1, jan./jun. 2002.

ARGENTINA. Corte Suprema de Justicia de la Nación. Ekmekdjian, Miguel Angel c/ Sofovich, Gerardo y otros. Julgado em 7 jul. 1992. Disponível em: www.saij.gob.ar/corte- 
suprema-justicia-nacion-federal-ciudad-autonoma-buenos-aires-ekmekdjian-miguel-angelsofovich-gerardo-otros-recurso-hecho-fa92000322-1992-07-07/123456789-223-0002-9otseupmocsollaf. Acesso em: 2 dez. 2017.

ARGENTINA. Ley n. 24.430: Constitución de la Nación Argentina. 1995. Disponível em: https://www.senado.gov.ar/bundles/senadoparlamentario/pdf/institucional/Ley24430. pdf. Acesso em: 18 maio 2019.

ARGENTINA. Ley n. 25.871: Ley de Migraciones. 2003. Disponível em: www.migraciones. gov.ar/pdf_varios/campana_grafica/pdf/Libro_Ley_25.871.pdf. Acesso em: 18 maio 2019.

ARGENTINA. Ley General n. 26.165: Reconocimiento y Protección al Refugiado. 2006. Disponível em: https://www.acnur.org/fileadmin/Documentos/BDL/2006/4658.pdf. Acesso em: 18 maio 2019.

ARGENTINA. Decreto nacional n. 1.034: Creación del Gabinete Nacional del Programa Siria en la órbita de la Jefatura de Gabinete de Ministros. 2016. Disponível em: https:// www.argentina.gob.ar/normativa/nacional/decreto-1034-2016-265715. Acesso em: 18 maio 2019.

BARBOZA, Estefânia Maria de Queiroz; BACK, Alessandra. A Proteção Normativa dos Refugiados Políticos na América Latina e no Brasil. In: GEDIEL, José Antônio Peres; GODOY, Gabriel Gualano de (org.). Refúgio e hospitalidade. Curitiba: Kairós Edições, 2016.

BARRETO, Luiz Paulo Teles Ferreira (org.). Refúgio no Brasil: a proteção brasileira aos refugiados e seu impacto nas Américas. Brasília: ACNUR/Ministério da Justiça, 2010.

BRASIL. [Constituição (1988)]. Constituição da República Federativa do Brasil de 1988. Brasília, DF: Presidência da República, 1988. Disponível em: www.planalto.gov.br/ ccivil_03/constituicao/constituicao.htm. Acesso em: 18 maio 2019.

BRASIL. Lei $\mathbf{n}^{\circ}$ 9.474, de 22 de julho de 1997. Define mecanismos para implementação do Estatuto dos Refugiados de 1951, e determina outras providências. Brasília, DF:

Presidência da República, 1997. Disponível em: http://www.planalto.gov.br/ccivil_03/leis/ 19474.htm. Acesso em: 18 maio 2019.

BRASIL. Lei $\mathbf{n}^{\circ}$ 13.445, de 24 de maio de 2017. Brasília, DF: Presidência da República, 2017. Disponível em: http://www.planalto.gov.br/ccivil_03/_ato2015-2018/2017/lei/ 113445.htm. Acesso em: 18 maio 2019.

BRASIL. Proposta de Emenda à Constituição n. 25. 2012. Disponível em: https://www25. senado.leg.br/web/atividade/materias/-/materia/105568. Acesso em: 18 maio 2019.

BRASIL. Comitê Nacional para Refugiados. Resolução Normativa n. 18. 2014. Disponível 
em: https://www.justica.gov.br/seus-direitos/migracoes1/refugio/anexos/resolucao-18-doupdf.pdf. Acesso em: 18 maio 2019.

BRASIL. Supremo Tribunal Federal. Informativo n. 502. 2008. Disponível em: www.stf. jus.br/arquivo/informativo/documento/informativo502.htm. Acesso em: 18 maio 2019.

BRASIL. Ministério da Justiça. Portaria do Ministério da Justiça n. 1.956. 2015.

Disponível em: www.lex.com.br/legis_27047025_portaria_n_1956_de_1_de_dezembro_ de_2015.aspx. Acesso em: 18 maio 2019.

BRUMAT, Leiza; TORRES, Rayen Amancay. La Ley de Migraciones 25 871: un caso de democracia participativa en Argentina. Estudios Políticos, n. 46, p. 55-77, 2015.

CALLUM, Stephanie Mc. El refugiado hiperreal. Formas legítimas e ilegítimas de ser refugiado en Argentina. Revista Temas de Antropología y Migración, Buenos Aires, n. 4, p. 30-53, dez. 2012.

CÁRITAS. Quem Somos. Brasília. Disponível em: www.caritas.org.br. Acesso em: 18 maio 2019.

CARNEIRO, Wellington Pereira; COLLAR, Janaina Matheus. Reflexões sobre a questão racial e refúgio no sistema brasileiro. In: SILVA, César Augusto S. da. Direitos Humanos e Refugiados. Dourados: UFGD, 2012.

CICOGNA, María Paula. Breve historia de los refugiados en Argentina durante el siglo XX. Historia Actual Online, Universidad de Cádiz, n. 18, p. 51-53, Inv. 2009a.

CICOGNA, María Paula. Refugiados en Argentina. El rol de las organizaciones de derechos humanos de la comunidad peruana. Papeles del CEIC, n. 50, p. 1-34, set. 2009 b. Disponível em: www.ehu.eus/ojs/index.php/papelesCEIC/article/viewFile/12259/11181. Acesso em: 18 maio 2019.

CICOGNA, María Paula. Solicitantes de Refugio y Refugiados em la Argentina ayer y hoy. Voces en el Fênix, n. 21, p. 50-55, 2012.

DOMINGUEZ, Juliana Arantes; BAENINGER, Rosana. Programa de Reassentamento de Refugiados no Brasil. In: ENCONTRO NACIONAL DE ESTUDOS POPULACIONAIS, 20., 2016, Foz do Iguaçu. Anais [...]. Foz do Iguaçu, 2016.

DURÃES, Marilene Gomes; OLIVEIRA, Camila Gomes. A Condição Jurídica dos Haitianos no Brasil: análise da resolução normativa 97/2012 do CNIg. In: PACIFICO, Andrea Maria C.; VIEIRA, Susana C. Direito Internacional e Direitos Humanos II. Florianópolis: CONPEDI, 2014.

GARBINI, Vanessa; SQUEFF, Tatiana Cardoso; SANTOS, Thomaz Francisco Araújo. A vulnerabilidade agravada dos refugiados na sociedade de consumo. Revista de Direito do Consumidor, São Paulo, v. 119, p. 19-49, 2018. 
GODOY, Gabriel Gualano. Refúgio, Hospitalidade e os Sujeitos Do Encontro. In: GEDIEL, José Antônio Peres; GODOY, Gabriel Gualano de (org.). Refúgio e hospitalidade. Curitiba: Kairós Edições, 2016.

JUBILUT, Liliana Lyra. O Direito Internacional dos Refugiados e sua Aplicação no Ordenamento Jurídico Brasileiro. São Paulo: Método, 2007.

JUBILUT, Liliana Lyra. Refugee Law and Protection in Brazil: a Model in South America? Journal of Refugee Studies, Oxford, v. 19, n. 1, p. 22-44, 2006.

\section{MADUREIRA, Andre de Lima. Direito Internacional dos Refugiados e Soluções}

Duráveis: instrumentos de proteção, abordagens atuais e a necessidade de novas respostas. 2015. Dissertação (Mestrado em Direito) - Universidade Católica de Santos, Santos, SP, 2015.

MARTIN, María. Sem fluência em idiomas, a PF depende de voluntários para atender refugiados. El País, 13 maio 2014. Disponível em: https://brasil.elpais.com/ brasil/2014/05/13/politica/1400012407_244755.html. Acesso em: 7 dez. 2017.

MILESI, Rosita; CARLET, Flávia. Refugiados e Políticas Públicas. In: SILVA, César Augusto S. da. Direitos Humanos e Refugiados. Dourados: UFGD, 2012.

MOREIRA, Carlos. Sufragio Transnacional: La experiência del voto de los extranjeros em Argentina. Revista Encrucijada Americana, Santiago de Chile, v. 5, n. 2, p. 70-73, mar. 2013.

NEJAMKIS, Lucila; NIEVAS, Jorge Álvarez. Migración y Refugio en la Argentina: un análisis desde la legislación actual. Revista Internacional de História Política e Cultura Jurídica, Rio de Janeiro, v. 4, n. 3, p. 445-463, 2012.

NICOLAO, Julieta. El Estado argentino ante el reto de las migraciones internacionales: reflexiones del reciente cambio de rumbo en la política migratoria argentina. Convergencia, v. 17, n. 53, p. 205-228, 2010.

NIEVAS, Jorge Alejandro Álvarez; BELLO, Juliana; MARCOGLIESE, María José. El reconocimiento de la condición de refugiado en la Argentina: estándares de protección a la luz de la Ley 26.165. Temas de Antropología y Migracíon, Buenos Aires, n. 4, 2012.

NOVICK, Susana Evolución reciente de la política migratoria argentina. In: INTERNATIONAL POPULATION CONFERENCE OF THE IUSSP, 25., 2005, Tours/ Francia. Anais [...]. Tours/Francia, 2005. Disponível em: http://www.demoscope.ru/ weekly/knigi/tours_2005/papers/iussp2005s50348.pdf. Acesso em: 18 maio 2019.

OLIVEIRA, Ione. Imigrantes e Refugiados para o Brasil após a Segunda Guerra Mundial. In: SIMPÓSIO NACIONAL DE HISTÓRIA, 27., 2013, Natal, Anais [...]. Natal: Anpuh, 2013. 
PEIXOTO, Leonardo Scofano D. Papel de Defensoria na defesa dos direitos dos refugiados e apátridas. Consultor Jurídico, São Paulo, 14 mar. 2017. Disponível em: https://www. conjur.com.br/2017-mar-14/tribuna-defensoria-papel-defensoria-defesa-direitos-refugiadosapatridas. Acesso em: 7 dez. 2017.

POSSE, Hortensia D. T. Gutierrez. El Derecho Internacional en la Constitución Nacional. In: CAMPOS, G. J. Bidart; SANDLER, H. R. (coord.). Estudios sobre la reforma constitucional de 1994. Depalma: Buenos Aires, 1995.

ROCIO, Andia. El Derecho de los Refugiados en la República Argentina del Bicentenario. In: CONGRESO LATINOAMERICANO DE CIENCIA POLÍTICA, 5., 2010, Buenos Aires. Anais [...]. Buenos Aires, 2010. Disponível em: cdsa.aacademica.org/000-036/728. pdf. Acesso em: 18 maio 2019.

ROGUET, Patrícia. Direitos e deveres dos refugiados na Lei n. 9.474/97. 2009. 108 F. Dissertação (Mestrado em Direito Político e Econômico) - Universidade Presbiteriana Mackenzie, São Paulo, 2009.

SOARES, Carina de Oliveira. Direito Internacional dos Refugiados e o Ordenamento Jurídico Brasileiro: análise da efetividade da proteção nacional. 2012. 252 f. Dissertação (Mestrado em Direito) - Universidade Federal de Alagoas, Maceió, 2012.

SUED, Gabriel. Proyecto oficialista para que voten los extranjeros. La Nacion, 11 ago. 2012. Disponível em: http://www.lanacion.com.ar/1498350-proyecto-oficialista-para-quevoten-los-extranjeros. Acesso em: 9 nov. 2017.

\section{NOTA}

O texto submetido à revista da Unichristus por nós, Tatiana Cardoso Squeff e Romeu Vaz Pinto Neto, intitulado originalmente como "Refúgio no Cone Sul: uma questão de "fórum shopping"?", refere-se a um recorte de uma estudo maior acerca dos procedimentos de recepção de Refugiados de Brasil e Argentina, entre outros, realizados de maneira separada, cujos dados foram levantados pelo autor Romeu. No caso, a análise dos pontos convergentes e divergentes, a partir da pesquisa prévia realizada, foi concretizada pela autora Tatiana. No caso conclusivo, no que pertine ao fórum shopping, reflete uma convergência entre os pensamentos dos dois autores. 